\title{
Analisis One Village One Product (OVOP) terhadap Penghasilan Tenaga Kerja Wanita di Kota Banda Aceh
}

\author{
Fanny Nailufar ${ }^{1)^{*}}$, Sufitrayati ${ }^{2)}$ \\ ${ }^{1,2)}$ Fakultas Ekonomi, Universitas Serambi Mekkah \\ e-mail: fanny.nailufar@serambimekkah.ac.id ${ }^{1 *}$
}

\begin{abstract}
Abstrak
Tujuan dari penelitian ini adalah untu dapat mengetahui perbedaan tingkat penghasilan tenaga kerja wanita pada Unit Usaha Produk Unggulan Gampong di Kota Banda Aceh sebelum adanya pembinaan dari program OVOP dan setelah adanya pembinaan dari program OVOP. Data yang digunakan dalam penelitian ini adalah data primer dan data sekunder. Data primer dengan melakukan wawancara terhadap responden yaitu tenaga kerja wanita serta menggunakan daftar pertanyaan yang sudah dipersiapkan sebelumnya. Data sekunder yang bersumber dari Badan Pusat Statistik (BPS), Dinas Perindustrian, Perdagangan, Koperasi dan Usaha Kecil Menengah (UKM) Kota Banda Aceh, Dinas Tenaga Kerja dan Kependudukan Provinsi Aceh dan instansi terkait lainnya. Penelitian ini dianalisa dengan menggunakan model analisis paired sampel t-test.. Hasil penelitian menunjukkan bahwa pembinaan yang diberikan melalui program OVOP memberikan dampak yang signifikan namun relatif sangat kecil terhadap penghasilan tenaga kerja wanita produk unggulan gampong yang menjadi UMKM binaan OVOP. Hal tesebut menujukkan bahwa program OVOP di Kota Banda Aceh belum memberikan dampak yang memuaskan bagi UMKM binaan OVOP.Menurut responden adapun indikator yang paling penting yang mereka butuhkan adalah fasilitas permodalan, fasilitas HKI dan kegiatan promosi serta pameran.
\end{abstract}

Kata Kunci: OVOP, Tenaga Kerja Wanita, Produk Unggulan Gampong

\section{PENDAHULUAN}

Program One Village One Product (OVOP) merupakan salah satu program pengembangan ekonomi kreatif yang menjadi fokus awal bagi Pemerintah Kota Banda Aceh melalui Dinas Perindustrian, Perdagangan, dan Koperasi (Disperindagkop) Kota Banda Aceh. Program yang mulai berjalan sejak tahun 2016 ini diluncurkan agar setiap desa mampu memanfaatkan potensi lokal daerah. Program tersebut juga diterapkan untuk menjawab tingginya angka pengangguran dan kemiskinan di Kota Banda Aceh. Berbagai kelompok usaha diberikan pembinaan dengan melibatkan berbagai lintas sektoral di ruang lingkup pemerintahan Aceh.

Menurut Kementerian Perindustrian Republik Indonesia dalam buku petunjuk teknis OVOP menjelaskan bahwa program pengembangan UMKM dengan pendekatan OVOP di sentra disusun sebagai acuan di tingkat pusat maupun di tingkat daerah dalam pelaksanaan seleksi dan pembinaan untuk meningkatkan kualitas dan produktifitas produk unggulan dan unik UMKM dengan pendekatan OVOP. Adapun Pembinaan dan pengembangan sentra OVOP dan produk OVOP menurut Kementerian Perindustrian Republik Indonesia antara lain berupa : a) Pelatihan; b) Pendampingan 
tenaga ahli; c) Bantuan sarana usaha; d) Promosi dan Pameran; e) Fasilitasi HKI; dan f) Fasilitas Permodalan.

Dalam Menjalankan program ini, Pemerintah kota Banda Aceh telah membentuk Task Force Pengembangan Ekonomi Kreatif (TF Ekraf) Kota Banda Aceh yang melibatkan unsur pemerintah, perguruan tinggi, dunia usaha dan komunitas/masyarakat. Sinergi empat unsur yang dikenal sebagai Quadro Helix Approach ini diyakini akan menghasilkan gerakan dan dampak yang kuat dalam pengembangan ekonomi kreatif Kota Banda Aceh.

Dari awal 2016, TF Ekraf telah menyusun berbagai program pengembangan ekonomi kreatif Kota Banda Aceh, dengan fokus awal pada program One Vilage One Product (OVOP). TF Ekraf bekerja sama dengan International Center for Aceh and Indian Ocean Studies (ICAIOS) telah mengirimkan enumerator ke 90 gampong yang ada di Kota Banda Aceh untuk melakukan survey tentang produk-produk Usaha Mikro Kecil dan Menengah (UMKM) dan menemukan sekitar 368 UMKM.

Dari 368 UMKM hasil survey tersebut TF Ekraf Kota Banda Aceh telah menetapkan 116 UMKM yang dianggap kreatif dan inovatif yang akan menguatkan kota Banda Aceh sebagai satu satunya kota di Aceh yang telah masuk dalam jaringan kota kreatif di Indonesia. Sejumlah 116 UMKM tersebut dipilih berdasarkan kriteria tertentu sesuai dengan ketentuan yang telah ditetapkan oleh Kementerian Perindustrian Republik Indonesia. Berdasarkan pemilihan 116 UMKM kreatif dan inovatif tersebut, TF Ekraf Kota Banda Aceh selanjutnya melakukan intervensi berbagai program pembinaan peningkatan bintang produk pada tahun 2017 berupa penguatan capasity building, peningkatan kualitas dan sertifikasi produk, program pendampingan, pemberian insentif serta perluasan pasar sesuai dengan ketersediaan anggaran.

Setiap Gampong memiliki sumber daya manusia yang potensial, kreatif dan inovatif untuk mengolah suatu produk, dikembangkan dan dijual sebagai suatu produk olahan yang berkualitas. Walaupun masalah pemasaran menjadi kendala dalam penjualan produk, maka diperlukan suatu kegiatan promosi yang efektif. Oleh karena itu dibutuhkan pendampingan dalam pemasaran produk unggulan suatu gampong. Sehingga dengan sendirinya produk unggulan gampong tersebut dapat dengan mudah dipasarkan baik dalam wilayah Kota Banda Aceh maupun luar Kota Banda Aceh.

Program ini menghasilkan berbagai unit usaha yang menjadi fokus binaan program OVOP dan mulai berkembang dengan sangat pesat. Hal yang menarik banyak tenaga kerja wanita yang juga bergabung dalam unit usaha tersebut. Hal ini tentu akan berdampak positif terhadap perekonomian para wanita yang bekerja di usaha binaan OVOP. Bahkan dapat membuka lapangan pekerjaan bagi masyarakat sekitar. 


\section{TINJAUAN PUSTAKA}

\section{One Village One Product (OVOP)}

Pendekatan One Village One Product (OVOP) mulai dikembangkan oleh Morihiko Hiramatsu, seorang mantan pejabat MITI yang terpilih menjadi Gubernur Oita pada tahun 1979. Masa jabatannya di Oita selama 6 periode (1979-2003) digunakan dengan sebaik-baiknya untuk mengentaskan kemiskinan warganya dengan menerapkan ide konsep pembangunan wilayah serta mengembangkan potensi daerah dengan melibatkan tokoh masyarakat, dan masyarakat itu sendiri sehingga termotivasi bangkit dan membangun daerahnya menjadi daerah yang makmur serta mensejahterakan masyarakat (Cahyani, 2013).

Di Indonesia, pendekatan OVOP mulai digagas pada tahun 2006 oleh Kementerian Perindustrian yang kemudian ditandai dengan terbitnya Instruksi Presiden No. 6/2007 tentang kebijakan percepatan pengembangan sektor riil dan pemberdayaan Usaha Mikro Kecil Menengah (UMKM) dan Peraturan Menperin No. 78/M-Ind/Per/9/2007 tentang peningkatan efektivitas pengembangan Industri Kecil Menengah (IKM) melalui pendekatan One Village One Product (OVOP) yang saling mengkait untuk mendorong produk lokal industri kecil dan menengah agar mampu bersaing di pasar global (Pasaribu et al., 2011).

Definisi OVOP di Indonesia dari Deputi Menteri Bidang Pengkajian Sumberdaya UKMK Kementerian Koperasi dan UKM RI adalah merupakan upaya pemerintah untuk meningkatkan nilai tambah produk unggulan daerah dalam rangka meningkatkan kesejahteraan masyarakat dalam wadah koperasi atau UKM. Tiga prinsip gerakan OVOP, yaitu: local tapi global yakni pengembangan pendekatan OVOP bertujuan untuk meningkatkan, mengembangkan dan memasarkan produk yang bisa menjadi sumber kebanggaan masyarakat setempat. Terutama yang bisa dipasarkan baik didalam maupun di luar negeri. Sehingga tercapai tujuan local tapi global. Kemandirian dan kreativitas agar masyarakat mampu bangkit dan kreatif. Yang terakhir adalah pengembangan sumberdaya manusia yaitu pemerintah daerah (Cahyani, 2013).

\section{Program dan Kegiatan One Village One Product (OVOP)}

Menurut Kementerian Perindustrian Republik Indonesia dalam buku petunjuk teknis OVOP, adapun program pengembangan UMKM dengan pendekatan OVOP di sentra meliputi:

1. Koordinasi dan sosialisasi program OVOP di provinsi.

2. Identifikasi, seleksi sentra dan produk OVOP di provinsi/ kabupaten/ kota serta sertifikas produk OVOP.

3. Pembinaan dan pengembangan sentra OVOP dan produk OVOP antara lain berupa pelatihan, pendampingan tenaga ahli, bantuan sarana usaha, promosi serta pameran, fasilitas HKI dan fasilitas permodalan.

4. Pemberian penghargaan OVOP

5. Klasifikasi dan Pembinaan Produk OVOP 
Klasifikasi produk OVOP Indonesia bersifat nasional. Penentuan klasifikasi berdasarkan dengan jumlah skor atas unsur-unsur yang dinilai. Klasifikasi produk OVOP Indonesia tertinggi adalah yang dapat mencapai skor 100 (sangat baik). Penilaian terhadap setiap jenis produk didasarkan pada unsur-unsur yang dinilai dalam format kuesioner. Selanjutnya, hasil penilaian produk dinyatakan dalam 5 (lima) peringkat/ tingkatan. Nilai skor tertinggi (91-100) ditetapkan dengan klasifikasi Bintang 5 (*****). Sedangkan nilai skor terendah (50-60) ditetapkan dengan klasifikasi Bintang $1(*)$.

\section{One Village One Product (OVOP) di Kota Banda Aceh}

Pemerintah kota Banda Aceh telah membentuk Task Force Pengembangan Ekonomi Kreatif (TF Ekraf) Kota Banda Aceh yang melibatkan unsur pemerintah, perguruan tinggi, dunia usaha dan komunitas/masyarakat. Sinergi empat unsur yang dikenal sebagai Quadro Helix Approach ini diyakini akan menghasilkan gerakan dan dampak yang kuat dalam pengembangan ekonomi kreatif Kota Banda Aceh. Adapun tahapan pelaksanaan program OVOP di Kota Banda Aceh yaitu:

1. Kesepakatan penandatanganan MoU antara Pemerintah Kota Banda Aceh melalui Dinas Perindustrian, Perdagangan dan Koperasi (Disperindagkop) dengan Universitas Syiah Kuala melalui Pusat Industri Keratif Universitas Syiah Kula atau Center for Creative Industry of Syiah Kuala University (CCIS)

2. Pembentukan Tim Task Force Ekonomi Kreatif (TF Ekraf) Kota Banda Aceh

3. Melakukan survey pemetaan produk industri kreatif UMKM di Kota Banda Aceh (Survey OVOP)

4. Penyusunan dan Peluncuran Buku Katalog Produk UMKM Banda Aceh 90 Gampong Tahun 2016

5. Melakukan penilaian dan klasifikasi produk OVOP sesuai dengan kriteria yang telah ditetapkan oleh Kementerian Perindustrian Republik Indonesia

6. Pemilihan 116 produk OVOP dan melakukan pembinaan dengan berbagai instrument seperti: pelatihan, pendampingan para ahli, promosi, pameran, ekspo dan pemberian insentif.

7. Menetapkan 3 produk unggulan gampong sesuai dengan kriteria penilaian. Adapun 3 produk tersebut yaitu: Produk Kopi (Ulee Kareng), Produk Ikan (Lampulo), Produk Kerajinan (Lambaro Skep).

8. Tahun 2018 TF Ekraf Kota Banda Aceh akan melakukan pembinaan untuk peningkatan kualitas produk OVOP dari bintang 2 ke bintang 1.

9. TF Ekraf Kota Banda Aceh akan mencoba menfasilitasi produk OVOP dengan membangun sebuah showroom untuk kegiatan promosi, pameran dan expo produk.

10. Tahun 2019 TF Ekraf Kota Banda Aceh akan melaksanakan quality control advance market untuk produk OVOP. 


\section{Upah dan Gaji}

Undang-undang Kecelakaan Kerja Tahun 1992 Nomor 3 mendefinisikan upah sebagai pembayaran berupa uang yang diterima oleh buruh sebagai ganti pekerjaan. Sementara itu menurut Poerwono (2014), upah adalah jumlah keseluruhan yang ditetapkan sebagai pengganti jasa yang telah dikeluarkan oleh tenaga kerja meliputi masa atau syarat-syarat tertentu. Upah atau gaji dapat dipandang sebagai imbalan atau balas jasa kepada para pekerja terhadap output produksi yang telah dihasilkan. Imbalan atau balas jasa ini disatu sisi merupakan hak yang harus didapat oleh para pekerja, namun di sisi lain merupakan perangsang untuk meningkatkan produktivitas (Tjiptoherijanto, 2008).

\section{Penelitian Terdahulu}

Badruddin (2011) dalam penelitiannya menganalisis Model Pengembangan Usaha Kecil Menengah dengan One Village One Product untuk Mengurangi Kemiskinan di Indonesia. Menurut analisis hasil penelitian tersebut menjelaskan bahawa pengembangan UKM menghadapi beberapa masalah yaitu kurangnya modal, kesulitan dalam pemasaran, struktur organisasi yang sederhana dengan deskripsi pekerjaan yang tidak standar, rendahnya manajemen mutu, keterbatasan sumber daya manusia, umumnya tidak memiliki akuntansi keuangan, rendahnya aspek legalitas, dan rendahnya kualitas teknologi. Menurutnya, strategi komprehensif untuk pengembangan UKM sangat krusial untuk dikembangkan guna mempercepat pertumbuhan UKM, untuk menghilangkan masalah UKM, dan membuat UKM menjadi kompetitif. Elemen yang saling terkait saat implementasi OVOP pada pengembangan UKM meminta kesediaan semua pihak terkait Triple Helix, dari Akademisi (A), Pebisnis (B), dan Pemerintah (G). Langkah-langkah kerja OVOP untuk penerapannya mencakup pemilihan produk spesifik lokal adalah identifikasi kekuatan produk dan kendala terkait untuk meningkatkan daya saing pasar lokal dan global, penerapan pengembangan produk (pengolahan dan pemasaran) untuk peningkatan nilai tambah dan pendapatan, dan implementasi Evaluasi untuk produk dan kinerja bisnis masa depan yang lebih baik. Berdasarkan pengembangan UKM, pemerintah dapat menurunkan angka kemiskinan di Indonesia.

Sementara itu menurut Natsuda, Igusa, \& Wiboonpongse (2012) membahas mengenai Pengembangan program One Tambon, One Product (OTOP) di Thailand, berdasarkan pengalaman awal gerakan One Village, One Product (OVOP) di Jepang. Diciptakan di Jepang sebagai sebuah kebijakan untuk membalikkan depopulasi pedesaan, Di Thailand, hal itu menjadi lebih terfokus pada pengentasan kemiskinan. Peneliti menjelaskan bahwa program OTOP telah memberi kesempatan kepada masyarakat untuk memasarkan hasil lokal dan menciptakan lapangan kerja. Penelitian ini mencakup survei sampel singkat OTOP provinsi Chiang Mai, dan sebuah studi kasus perusahaan.

Menurut Hermuningsih \& Dewi (2014), Salah satu peluang pengembangan SMI dan UKM adalah melalui program pengembangan komoditas daerah. Pasalnya, masing-masing daerah memiliki 
keunikan tersendiri yang membuat keunggulan komparatif. Konsep kawasan komoditi tersebut benarbenar mereplikasi kesuksesan masyarakat dan pemerintah Jepang dan Thailand yang membuktikan keandalan model One Village One Product (OVOP) yang dibangun dengan keunggulan komparatif. Untuk mendukung program ini, langkah pertama adalah memetakan dan mengidentifikasi produk unggulan, memilih koperasi potensial, dan mengamati kesesuaian potensi sumber daya alam dan sumber daya manusia yang memiliki keterampilan, etos kerja, semangat kerja sama. Dibutuhkan konsistensi kebijakan dan program, jika perlu, menyiapkan proyek laboratorium sosial yang menjadi acuan semua pihak mulai tahun 2011 sampai 2014, Kementrian Koperasi dan UKM Indonesia mengembangkan produk terbaik OVOP di 100 titik di 33 provinsi berdasarkan peningkatan kualitas dan daya saing untuk membuat produk terbaik bernilai tambah melalui pengolahan industri (value chains), pengemasan, pemasaran terpadu dan perluasan jaringan lainnya. Kegiatan pengembangan memprioritaskan dan fokus pada daerah dan pasar tertentu sehingga hasil yang dicapai dari manajemen akan terukur, akuntabel, efektif, efisien, dan dapat dipasarkan.

\section{Kerangka Penelitian}

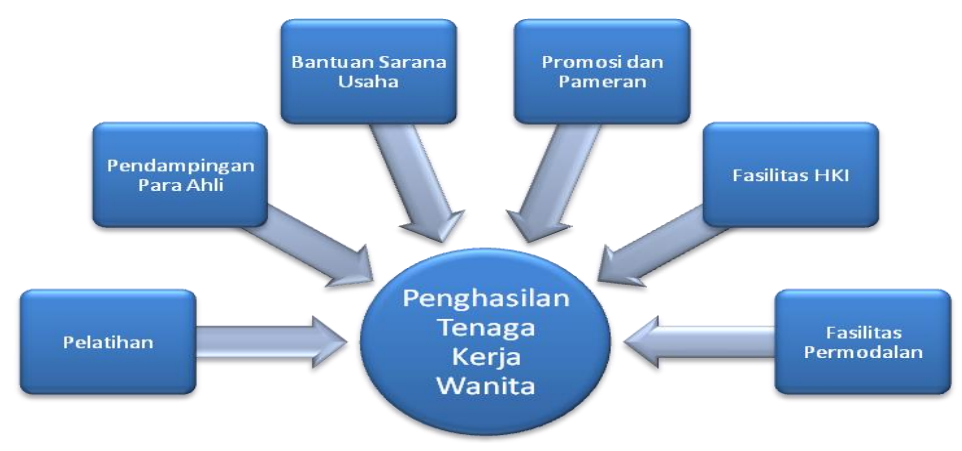

Gambar 1. Kerangka Penelitian

\section{Hipotesis}

$\mathrm{Ho}=$ Rata-rata penghasilan sebelum adanya program $\mathrm{OVOP}=$ Rata-rata penghasilan setelah adanya program OVOP,

$\mathrm{H} 1=$ Rata-rata penghasilan sebelum adanya program OVOP $\neq$ Rata-rata penghasilan setelah adanya program OVOP.

\section{METODE PENELITIAN}

Penelitian dilaksanakan di Kota Banda Aceh yang merupakan Ibukota Provinsi Aceh. Penelitian ini akan membahas mengenai tenaga kerja wanita di Kota Banda Aceh. Pembahasan dari penelitian ini hanya terbatas pada masalah mengenai perbedaan penghasilan tenaga kerja wanita sebelum adanya program One Village, One Product (OVOP) dan setelah adanya program One Village, One Product (OVOP) di Kota Banda Aceh. Dalam hal ini tenaga kerja yang dimaksud yaitu tenaga kerja wanita yang berkerja pada unit usaha produk unggulan gampong di Kota Banda Aceh. 
Dalam pengambilan sampel penelitian ini peneliti menyusun kriteria tertentu agar responden yang dipilih merupakan responden yang tepat untuk kajian penelitian ini. Adapun kriteria pemilihan UMKM dan responden tenaga kerja wanita tersebut yaitu:

1. UMKM yang mendapatkan pembinaan dari program OVOP

2. UMKM yang telah berdiri selama 2 tahun sebelum Program OVOP dijalankan.

3. UMKM yang masih berjalan aktivitas produksi setelah pembinaan dari OVOP sampai dengan sekarang ini

4. UMKM yang memiliki tenaga kerja wanita yang telah bekerja di UMKM tersebut selama 2 tahun sebelum Program OVOP dijalankan

5. UMKM yang memiliki tenaga kerja wanita yang masih bekerja di UMKM tersebut setelah pembinaan dari OVOP sampai dengan sekarang ini.

Dari kriteria tersebut dapat dilihat hasil penetapan responden di tabel 4.1 dibawah ini:

Tabel 1. Jumlah Responden Berdasarkan Kriteria dalam Penelitian

\begin{tabular}{lcc}
\hline \multicolumn{1}{c}{ Kriteria } & $\begin{array}{c}\text { Jumlah } \\
\text { Responden }\end{array}$ \\
\hline 1. & 116 \\
\hline 2. UMKM yang mendapatkan pembinaan dari program OVOP & 83 \\
& dijalankan. & 65 \\
\hline 3. & $\begin{array}{l}\text { UMKM yang masih berjalan aktivitas produksi setelah pembinaan dari } \\
\text { OVOP sampai dengan sekarang ini }\end{array}$ & 47 \\
\hline 4. & $\begin{array}{l}\text { UMKM yang memiliki tenaga kerja wanita yang telah bekerja di UMKM } \\
\text { tersebut selama 2 tahun sebelum Program OVOP dijalankan }\end{array}$ \\
\hline 5. & $\begin{array}{l}\text { UMKM yang memiliki tenaga kerja wanita yang masih bekerja di UMKM } \\
\text { tersebut setelah pembinaan dari OVOP sampai dengan sekarang ini. }\end{array}$ \\
\hline
\end{tabular}

Sumber: Task Force Ekonomi Kreatif Kota Banda Aceh (diolah)

Dari tabel diatas dapat dilihat bahwa dari populasi penelitian sebanyak 116 UMKM maka penelitian ini mengambil sampel sebanyak 32 responden tenaga kerja wanita UMKM binaan OVOP.

Jenis data yang digunakan adalah data primer dan data sekunder. Data primer dengan melakukan wawancara terhadap responden yaitu tenaga kerja wanita serta menggunakan daftar pertanyaan berupa kuisioner yang sudah dipersiapkan sebelumnya. Data sekunder adalah data yang diperoleh dari sumber tidak langsung. Data sekunder ini diperoleh dari Badan Pusat Statistik (BPS) Aceh, Dinas Perindustrian, Perdagangan, Koperasi dan Usaha Kecil Menegah (UKM) Kota Banda Aceh, Dinas Tenaga Kerja dan Mobilitas Penduduk Provinsi Aceh dan berbagai pustaka yang dapat membantu dalam pembahasan permasalahan yang ada.

Penelitian ini menggunakan teknik analisis data paired sample t-test, dimana merupakan salah satu jenis uji statistika yang bertujuan untuk membandingkan rata-rata dua grup yang saling 
berpasangan. Sampel berpasangan dapat diartikan sebagai sebuah sampel dengan subjek yang sama namun mengalami 2 perlakuan atau pengukuran yang berbeda, yaitu pengukuran sebelum dan sesudah dilakukan sebuah treatment. Adapun berikut Rumus t-test yang digunakan untuk sampel berpasangan (paired) adalah:

$$
t=\frac{\bar{x}_{1}-\bar{x}_{2}}{\sqrt{\frac{s_{1}^{2}}{n_{1}}+\frac{s_{2}^{2}}{n_{2}}-2 r\left(\frac{s_{1}}{\sqrt{n_{1}}}\right)\left(\frac{s_{2}}{\sqrt{n_{2}}}\right)}}
$$

Keterangan:

$\bar{x}_{1}=$ Rata-rata penghasilan sebelum adanya pembinaan program OVOP

$\bar{x}_{2}=$ Rata-rata penghasilan sebelum adanya pembinaan program OVOP

$\mathrm{S}_{1}, \mathrm{~S}_{2}=$ Simpangan baku

$\mathrm{S}_{1}^{2}, \mathrm{~S}_{2}^{2}=$ Varians

$\mathrm{r} \quad=$ Korelasi antara keduanya

\section{HASIL DAN PEMBAHASAN}

Uji Reliabilitas Instrumen

Tabel 2. Reliability Statistics

\begin{tabular}{cc}
\hline Cronbach's Alpha & N of Items \\
\hline .863 & 26 \\
\hline Sumber data: output SPSS yang diolah, 2018
\end{tabular}

Dalam melakukan pengujian reliabilitas instrument, dapat diketahui bahwa hasil cronbach's alpha instrument berupa 0,863 >0,60. Hasil ini menunjukkan bahwa dengan sejumlah 26 item pertanyaan kuisioner menunjukkan bahwa pertanyaan dari kuisioner ini dianggap sangat realible (lihat tabel 2).

\section{Analisis Deskriptif Statistik}

Tabel 3. Descriptive Statistics

\begin{tabular}{lcrrrr}
\hline & $\mathrm{N}$ & Minimum & Maximum & Mean & Std. Deviation \\
\hline $\begin{array}{l}\text { Penghasilan Sebelum } \\
\text { OVOP }\end{array}$ & 32 & .7 & 31.0 & 13.225 & 8.3934 \\
\hline $\begin{array}{l}\text { Penghasilan Sesudah } \\
\text { OVOP }\end{array}$ & 32 & 1.0 & 35.0 & 14.813 & 8.9522 \\
\hline Pelatihan & 32 & 2.60 & 5.00 & 4.0063 & .58472 \\
\hline Pendamping Ahli & 32 & 2.60 & 5.00 & 3.3375 & .51666 \\
\hline Bantuan Sarana Usaha & 32 & 1.75 & 4.00 & 2.5625 & .65685 \\
\hline Promosi dan Pameran & 32 & 2.75 & 5.00 & 3.8125 & .66296 \\
\hline Fasilitas HKI & 32 & 3.00 & 5.00 & 3.8594 & .71825 \\
\hline Fasilitas Permodalan & 32 & 1.50 & 4.00 & 2.2656 & .54602 \\
\hline
\end{tabular}

Sumber data: output SPSS yang diolah, 2018 
Berdasarkan analisis deskriptif statististik menunjukkan bahwa penghasilan minimum tenaga kerja wanita sebelum adanya pembinaan program OVOP yaitu Rp. 700.000/bulan dan penghasilan maksimum sebesar Rp. 31.000.000/bulan. Sedangkan setelah adanya pembinaan program OVOP penghasilan minimum tenaga kerja wanita sebesar Rp. 1.000.000/bulan dan penghasilan maksimum sebesar Rp. 35.000.000/ bulan.

\section{Uji Paired Samples Statistics}

Tabel 4. Paired Samples Statistics

\begin{tabular}{llcccc}
\hline & Mean & N & $\begin{array}{c}\text { Std. } \\
\text { Deviation }\end{array}$ & Std. Error Mean \\
\hline Pair 1 & $\begin{array}{l}\text { Penghasilan } \\
\text { Sesudah OVOP }\end{array}$ & 14.813 & 32 & 8.9522 & 1.5825 \\
& $\begin{array}{l}\text { Penghasilan } \\
\text { Sebelum OVOP }\end{array}$ & 13.225 & 32 & 8.3934 & 1.4838 \\
\hline
\end{tabular}

Sumber data: output SPSS yang diolah, 2018

Pengujian paired samples statistics menunjukkan bahwa rata-rata penghasilan tenaga kerja wanita sebelum OVOP yaitu Rp. 13.225.000/bulan sedangkan setelah adanya pembinaan program OVOP rata-rata penghasilan tenaga kerja wanita meningkat sebesar Rp. 14.813.000/bulan.

\section{Analisis Paired Samples Test}

Tabel 5. Paired Samples Test

\begin{tabular}{|c|c|c|c|c|c|c|c|c|c|}
\hline & & \multicolumn{5}{|c|}{ Paired Differences } & \multirow[b]{3}{*}{$\mathrm{t}$} & \multirow[b]{3}{*}{$\mathrm{df}$} & \multirow{3}{*}{$\begin{array}{l}\text { Sig. (2- } \\
\text { tailed) }\end{array}$} \\
\hline & & \multirow[b]{2}{*}{ Mean } & \multirow{2}{*}{$\begin{array}{c}\text { Std. } \\
\text { Deviatio } \\
\text { n }\end{array}$} & \multirow{2}{*}{$\begin{array}{l}\text { Std. } \\
\text { Error } \\
\text { Mean }\end{array}$} & \multicolumn{2}{|c|}{$\begin{array}{l}95 \% \text { Confidence } \\
\text { Interval of the } \\
\text { Difference } \\
\end{array}$} & & & \\
\hline & & & & & Lower & Upper & & & \\
\hline $\begin{array}{l}\text { Pair } \\
1\end{array}$ & $\begin{array}{l}\text { Penghasila } \\
\text { n Sesudah } \\
\text { OVOP - } \\
\text { Penghasila } \\
\text { n Sebelum } \\
\text { OVOP }\end{array}$ & 1.5875 & 1.2533 & .2216 & $\begin{array}{r}1.135 \\
6\end{array}$ & 2.0394 & 7.165 & 31 & .000 \\
\hline
\end{tabular}

Sumber data: output SPSS yang diolah, 2018

Berdasarkan tabel 5, adapun hasil penelitian ini menunjukkan bahwa penghasilan tenaga kerja wanita UMKM yang mendapatkan pembinaan OVOP hanya mengalami kenaikan yang relatif sangat kecil dengan rata-rata jumlah peningkatan sebesar Rp. 1.587.500/bulan.

\section{Uji One Sample Test}

Dari pengujian one sample test (tabel. 6) dapat dilihat bahwa menurut responden indikator pembinaan OVOP yang paling penting berturut adalah fasilitas permodalan, fasilitas HKI dan promosi serta pameran. Sementara itu indiator yang dianggap tidak penting berturut-turut adalah bantuan sarana usaha, pendampingan para ahli dan pelatihan. Hal tersebut menunjukkan bahwa indikator 
Tabel 6. One-Sample Test

\begin{tabular}{|c|c|c|c|c|c|c|}
\hline & \multicolumn{6}{|c|}{ Test Value $=3$} \\
\hline & \multirow[b]{2}{*}{$\mathrm{t}$} & \multirow[b]{2}{*}{$\mathrm{df}$} & \multirow[b]{2}{*}{ Sig. (2-tailed) } & \multirow{2}{*}{$\begin{array}{c}\text { Mean } \\
\text { Difference }\end{array}$} & \multicolumn{2}{|c|}{$\begin{array}{c}95 \% \text { Confidence Interval } \\
\text { of the Difference }\end{array}$} \\
\hline & & & & & Lower & Upper \\
\hline PR1 & -.279 & 31 & .782 & -.063 & -.52 & .39 \\
\hline PR2 & 0.000 & 31 & 1.000 & 0.000 & -.44 & .44 \\
\hline PR3 & .162 & 31 & .872 & .031 & -.36 & .42 \\
\hline PR4 & 3.283 & 31 & .003 & .531 & .20 & .86 \\
\hline PR5 & 8.979 & 31 & .000 & 1.094 & .85 & 1.34 \\
\hline PR6 & 15.574 & 31 & .000 & 1.656 & 1.44 & 1.87 \\
\hline
\end{tabular}

Sumber data: output SPSS yang diolah, 2018

fasilitas permodalan, fasilitas HKI dan promosi serta pamera harus menjadi indikator prioritas yang sangat dibutuhkan oleh responden agar program pembinaan OVOP dapat memberikan dampak yang cukup signifikan bagi tenaga kerja wanita unit usaha produk unggulan gampong binaan program OVOP.

Dari pengujian one sample test (tabel 6) dapat dilihat bahwa menurut responden indikator pembinaan OVOP yang paling penting berturut adalah fasilitas permodalan, fasilitas HKI dan promosi serta pameran. Sementara itu indiator yang dianggap tidak penting berturut-turut adalah bantuan sarana usaha, pendampingan para ahli dan pelatihan. Hal tersebut menunjukkan bahwa indikator fasilitas permodalan, fasilitas HKI dan promosi serta pamera harus menjadi indikator prioritas yang sangat dibutuhkan oleh responden agar program pembinaan OVOP dapat memberikan dampak yang cukup signifikan bagi tenaga kerja wanita unit usaha produk unggulan gampong binaan program OVOP.

\section{KESIMPULAN DAN SARAN}

1. Dari hasil penelitian menujukkan bahwa pembinaan yang diberikan melalui program OVOP memberikan dampak yang relatif sangat kecil terhadap penghasilan tenaga kerja wanita produk unggulan gampong yang menjadi UMKM binaan OVOP. Hal tesebut menujukkan bahwa program OVOP di Kota Banda Aceh belum memberikan dampak yang memuaskan bagi UMKM binaan OVOP.

2. Menurut responden adapun indikator yang paling penting yang mereka butuhkan adalah fasilitas permodalan, fasilitas HKI dan kegiatan promosi serta pameran. Oleh karena itu diharapkan pihak terkait dapat menfokuskan pembinaan melalui program OVOP dengan memaksimalkan ketiga indikator tersebut agar dapat memberikan dampak dan kepuasan bagi responden UMKM binaan OVOP.

3. Pemeritah juga diharapkan untuk dapat memberikan kontribusi yang maksimal dengan menyediakan anggaran yang sesuai dengan kebutuhan program OVOP. Sehingga setiap indicator 
pembinaan OVOP bias dijalankan dengan baik dan memberikan pengaruh yang signifikan bagi UMKM produk unggulan gampong Kota Banda Aceh.

\section{REFERENSI}

Badrudin, Rudy. 2011. Model Pengembangan Usaha Mikro Kecil Menengah dengan One Village One Product untuk Mengurangi Kemiskinan di Indonesia. Jurnal Akuntansi \& Manajemen. Vol. 22, No.1. Hal:39-66.

Cahyani, R. R. 2013. Pendekatan One Village One Product (OVOP) untuk Meningkatkan Kreativitas UMKM dan Kesejahteraan Masyarakat. Sustainable Competitive Advantage (SCA). 3(1). Retrieved from http://jp.feb.unsoed.ac.id/index.php/sca-1/article/viewFile/249/254

Hermuningsih, Sri \& Dewi Kusuma Wardani. 2014. Pendekatan OVOP (One Village One Product) sebagai Program Pemgembangan dan Kebijakan IKM dan UMKM dengan Keunggulan Daerah. Jogja Ekonomi Bisnis Forum.

Kementerian Perindustrian. 2010. Pedoman Umum dan Petunjuk Teknis Pengembangan IKM melalui Pendekatan Satu Desa Satu Produk (One Village One Product-OVOP), Jakarta: Dirjen IKM Kementerian Perindustrian.

Natsuda, K., Igusa, K., \& Wiboonpongse, A. (2012). One Village One Product-Rural Development Strategy in Asia: the case of OTOP in Thailand. Vdots Journal of Development Vdots, (11). https://doi.org/10.1080/02255189.2012.715082

Pasaribu, Sahat M. 2011. Pengembangan Agro-Industri Perdesaan Dengan Pendekatan One Village One Product (OVOP). Forum Penelitian Agro Ekonomi. Vol. 29. No. 1. Hal:1-11.

Tjiptoherianto, Prijono. 2008. Sumber Daya Manusia Dalam Pembangunan Nasional. Lembaga Penerbit Fakultas Ekonomi Universitas Indonesia. 